\title{
Mother and Caregiver Sensitivity Over Time: Predicting Language and Academic Outcomes With Variable- and Person-Centered Approaches
}

\author{
Kathy Hirsh-Pasek, Temple University
}

Margaret Burchinal, University of North Carolina

\begin{abstract}
Sensitive and responsive caregiving is associated with better cognitive and language outcomes. Using the longitudinal data set from the National Institute for Child Health and Human Development (NICHD) Study of Early Child Care and Youth Development, this study asks how changes in the sensitivity of both mothers and caregivers from 6 months to 6 years relates to language and academic outcomes at the start of formal schooling. Three questions are posed: (1) How variable is the quality of caregiving that children experience from mothers and child care providers during early childhood? (2) Do children benefit from both sensitive parents and sensitive caregivers? (3) Are changes in sensitivity over time related to cognitive and language outcomes at the end of preschool and the beginning of formal education? Person-centered and variable-centered analyses revealed that children experience changing patterns of sensitivity across time, that children benefit from sensitive interactions with all adults, and that changes in the sensitivity children experience across time are associated with both language and cognitive outcomes.
\end{abstract}

Stimulating and responsive caregiving environments promote social and cognitive development (Shonkoff \& Philips, 2000). A substantial body of research attests to this claim (see Bornstein \& Tamis-LeMonda, 1989, and TamisLeMonda \& Bornstein, 2002, for reviews). Adults who take turns in interactions with young children, share periods of joint focus, and express positive affect provide infants and toddlers with a secure base for exploring their world

Kathy Hirsh-Pasek, Department of Psychology; Margaret Burchinal, Frank Porter Graham Child Development Institute.

This research was supported by NICHD grant HD25455-07 to both authors.

Correspondences should be directed to Dr. Kathy Hirsh-Pasek, Psychology, Temple University, Weiss Hall, 13th and Cecil B. Moore, Philadelphia, PA 19128. E-mail: khirshpa@temple.edu.

Merrill-Palmer Quarterly, July 2006, Vol. 52, No. 3, pp. 449-485. Copyright @2006 by Wayne State University Press, Detroit, MI 48201. 
and with the scaffolding needed to facilitate language and cognitive growth (Bradley et al., 1989; Bronfenbrenner \& Morris, 1998; Clarke-Stewart, 1973; Howes, 2000; Katz, 2000; Tomasello \& Farrar, 1986). For example, evidence strongly suggests that a greater amount and a larger diversity of verbal stimulation foster earlier and richer language outcomes in terms of both vocabulary and grammar (Beebe, Jaffe, \& Lachman, 1992; Hart \& Risley, 1995, 1999; Huttenlocher, Haight, Bryk, Seltzer, \& Lyons, 1991; Snow, 1986; TamisLeMonda, Bornstein, \& Baumwell, 2001; see Hoff, in progress, for a review).

There is little debate that sensitive and stimulating caregiving plays an important role in promoting cognitive and language development. Most research, however, treats stimulation and responsiveness as a static variable and asks how characteristics of the mother-child or caregiver-child interaction at one point in time or averaged over time affects either concurrent or later child behavior. Little is known about how individual variation in parental or caregiver sensitivity over time affects child outcomes or even whether parental and caregiver sensitivity is constant over time (but see Bornstein \& Tamis-LeMonda, 1989; Landry, Smith, Swank, Assel, \& Vellet, 2001; Landry, Smith, Swank, \& Miller-Loncar, 2000; Tamis-LeMonda \& Bornstein, 2002). This study uses the longitudinal data set from the NICHD Study of Early Child Care and Youth Development to examine this issue. It investigates (1) the degree to which children from 6 to 54 months receive consistent or inconsistent patterns of stimulation and responsiveness from parents and changing child care providers, and (2) the extent to which patterns of change in the responsiveness children receive over time predicts their development at the start of formal schooling. Two statistical procedures not widely used in the cognitive literature are used to address these questions.

Sensitive and stimulating parenting. Stimulating and responsive parenting in early childhood is one of the strongest predictors of children's later language, cognitive, and social skills (Bronfenbrenner \& Morris, 1998; Sameroff \& Seifer, 1983). Distal measures show that homes rich in ageappropriate toys, reading materials, and conversation provide opportunities for learning that consistently predict higher reading and math scores during elementary and middle school (Bradley \& Corwyn, 2002; Bradley et al., 1989; Bradley, Corwyn, Burchinal, Pipes McAdoo, \& Garcia Coll, 2001; Senechal \& LeFevre, 2002; Whitehurst, Arnold, Epstein, \& Angell, 1994; among many others), reading competency in second grade (Scarborough, Dobrich, \& Hager, 1991), and even 11th-grade reading comprehension (Cunningham \& Stanovich, 1997; Cunningham, Stanovich, \& West, 1994). Children's language skills are even more strongly related to proximal measures of quality in parent-child interaction, such as sensitivity cooperation, acceptance, and responsiveness (Landry et al., 2001; Tamis-LeMonda \& Bornstein, 2002; Wakschlag \& Hans, 1999). Parental warmth demonstrated as open dis- 
plays of affection, physical or verbal reinforcement, and sensitivity to children's requests and feelings are also significantly associated with academic achievement and cognitive growth (Bornstein \& Tamis-LeMonda, 1989; Burchinal, Campbell, Bryant, Wasik, \& Ramey, 1997; Howes, Phillips, \& Whitebook, 1992; Landry et al., 2001; Morrison \& Cooney, 2002). The affective quality of mother-child interactions in early childhood is further related to early cognitive competencies, such as mental ability scores at age 4 , school readiness skills at age 5 and 6 , IQ scores at age 6 , and vocabulary and mathematics performance at age 12 (Estrada, Arsenio, Hess, \& Holloway, 1987). Responsiveness of parents in terms of diversity of language also relates to later proficiency (Weizman \& Snow, 2001).

Sensitivity and stimulation in child care. Although the role of sensitive input has been more extensively explored in the parenting literature, responsive and stimulating behavior by caregivers also relates independently to child outcomes. At the distal level, all large, multi-site, observational studies of children's cognitive and language development (Howes et al., 1992; Love et al., 2003; NICHD Early Child Care Research Network [ECCRN], 2000, 2002; Peisner-Feinberg \& Burchinal, 1997; Zill, 1999) and most smaller studies (Burchinal, Roberts, Nabors, \& Bryant, 1996; Burchinal et al., 2000; Dunn, 1993; Kontos, 1991; McCartney, 1984; Schliecker, White, \& Jacobs, 1991) find a direct relationship between the amount of sensitivity in the environment and cognitive and language outcomes. This link between child care quality and child outcomes has been observed in child care homes and relative care as well as in center care (Clarke-Stewart, Vandell, Burchinal, O'Brien, \& McCartney, 2002; Kontos, Howes, Shinn, \& Galinsky, 1997; NICHD ECCRN, 2000, 2002).

In language development, several studies looked more proximally at the caregiver's interaction with the target child. Children whose caregivers were more responsive and stimulating showed higher language scores and larger gains over time (Burchinal et al., 2000). Studies also find direct relationships among responsiveness, stimulation, and language outcomes (McCartney, 1984; NICHD ECCRN, 2000).

The research relating parental and child care interaction with child outcomes has provided powerful information on environmental predictors of cognitive and language success. Yet, research exploring this question generally relies upon group data in which the predictors of stimulation and responsiveness are measured at only one point in time (Hart \& Risley, 1995; Hoff \& Naigles, 2002; Huttenlocher et al., 1991; Newport, Gleitman, \& Gleitman, 1977), are averaged over time (see NICHD ECCRN, 2000, and Tamis-LeMonda \& Bornstein 2002, for a review of their work), or are treated as a time-varying covariate (Burchinal et al., 1997; NICHD ECCRN, 2004). Although these studies are informative, they generally 
mask individual and group variation that might accrue across time. These investigations do not allow us to ask whether children are receiving constant amounts of sensitivity over time from the parents and caregivers or whether changes in stimulation and sensitivity that they receive over time have any notable effects on child outcomes. That is, they do not treat the sensitivity and stimulation that children receive as a dynamic variable.

Limited evidence suggests that changes in parental sensitivity over time relate to changes in child outcomes (see Bornstein \& Tamis-LeMonda, 1989; Landry et al., 2000, 2001; NICHD ECCRN \& Duncan, 2003; TamisLeMonda \& Bornstein, 2002). Landry et al. (2001), for example, found that children who had highly sensitive parents in the first 3 years of life followed by lower sensitivity did not perform as well as children who had consistently high sensitivity across early childhood. Bornstein and TamisLeMonda (1989) also looked at patterns of sensitivity and stimulation over time. A longitudinal study of 40 mother-child dyads when the children were between 9 months and 19 months of age revealed that prompt, contingent, and appropriate responses to children's behaviors had dramatic effects on children's later language and cognitive growth. In both the Landry et al. (2001) and the Bornstein and Tamis-LeMonda (1989) studies, more sensitive parents were more stimulating. Operational definitions of sensitivity often embed qualities of stimulation.

The current study expands upon these longitudinal investigations in three ways. First, studies of patterns of change in responsiveness over time and its relationship to cognitive and language outcomes focus almost exclusively on sensitivity/stimulation as it is experienced in the parentchild interaction. With a large proportion of children in alternative care, it is important to ask how sensitivity that emerges in both parent and caregiver settings relates (independently and jointly) to child outcomes. Second, available longitudinal studies look at development only until 4 years of age. This study pushes the developmental envelope by asking how patterns of change in sensitivity and responsiveness from mothers and caregivers across time affects cognitive and language outcomes at the end of preschool and after the transition to school in first grade. Finally, this study introduces two relatively new analytic techniques to address questions about relations between sensitivity and responsiveness and child outcome. The variable-centered approach estimates changes in sensitivity and responsiveness in terms of individual growth curves and uses individual differences in growth curve parameters as predictors of child outcomes. In contrast, the person-centered approach identifies types of patterns in the change in sensitivity/stimulation over time, using types as predictors that might differentially relate to outcomes. 


\section{Methods}

\section{Participants}

The NICHD Study of Early Child Care and Youth Development offers a unique opportunity to address these issues with a large geographically, ethnically, and economically diverse population. Children born in hospitals at 10 geographic sites in the United States were followed from birth to first grade. Families were recruited shortly after the child's birth in 1991. For a full description of the sample recruitment and distribution see NICHD ECCRN (2004). A total of 1,097 of the 1,364 original participants continued in the study through 54 months and form the sample for the current study. Mothers of the children in this sample had an average of 14.2 years of education $(S D=2.51) ; 18 \%$ were single; and average family income was about four times the poverty threshold $(M=3.7, S D=2.74)$. About threefourths of the children were European American, non-Hispanic. Importantly, although the analysis sample is not nationally normed, it reflects a diverse range of family backgrounds present in the United States.

\section{Procedure}

Infants and their mothers were seen in the lab or in their homes repeatedly from the time the child was 1 month of age until the child was in first grade. Mothers also responded to questions in a telephone interview that was given every 3 months up until age 36 months and approximately every 4 months thereafter. Data for this study were collected using multiple methods: standardized observations of the child or the mother and child, telephone interviews for the mother, and lab-based standardized tests for child outcome measures. Below we outline the measures that were used to provide demographic data, the predictor variable of sensitivity from both mothers and caregivers, and child outcome variables in language, attention, and academic achievement at 54 months of age and in first grade. These outcome measures were collected at the end of preschool (54 months) and in the spring of their first grade.

\section{Measures}

\section{PREDICTOR VARIABLES}

Demographic measures. During home interviews at 1 month, mothers reported their education (in years) and the study children's sex and ethnicity (non-Hispanic African American, non-Hispanic European American, 
Hispanic, or other). The presence of a husband or partner in the home was reported in telephone interviews spaced every 3 to 4 months. Partner status was the proportion of 3- to 4-month intervals during which the mother reported the presence of a husband or partner in the home. Mothers reported family income at 15, 24, 36, and 54 months. Income-to-needs ratios were calculated from U.S. Census Bureau tables as the ratio of family income to the appropriate poverty threshold for each household size and number of children less than 18 years of age. For example, an income of $\$ 15,455$ in 1995 for a family of four would have an income/needs ratio of 1 . Incometo-needs ratio, maternal level of education, child ethnicity, child gender, and the site of data collection were used as control variables in all analyses.

Sensitivity. This measure was an amalgamation of both sensitivity and stimulation as experienced by the child and served as the main predictor variable. It was tabulated from two sources: sensitivity/stimulation in interactions between the child and his or her mother and between the child and his or her child care provider. Importantly, the sensitivity experienced by the child over time from parent and caregiver was the predictor variable, rather than the person delivering sensitive or insensitive care. This becomes critically important in the later analyses because the person delivering sensitive or stimulating care over time for parents will involve a stable person, while the person delivering the sensitive or stimulating care in the child care setting will largely vary over time.

Maternal sensitivity. Qualities of maternal sensitivity and stimulation were rated from a videotaped, semi-structured mother-child dyadic play procedure that occurred in the home when children were 6 and 15 months of age, in the lab when they were 24,36 , and 54 months of age, and in first grade (NICHD ECCRN, 1999). All tapes were coded at a central location by coders who were unacquainted with the family or child care history. The play procedure was designed to elicit interactions that occur between mother and child in the context of the home environment. Maternal stimulation of cognitive development was also evaluated as a part of this interaction using ratings for the number and quality of activities presumed to enhance perceptual, cognitive, linguistic, and physical development.

At 6, 15, and 24 months, composite maternal sensitivity scores were created as the mean of four 4-point ratings: maternal stimulation, maternal sensitivity to child non-distress, intrusiveness (reverse scored), and positive regard. At 36 and 54 months and first grade, the sensitivity composite was computed as the mean of four 7-point ratings (prorated back to a 4-point scale by multiplying by 4/7). The ratings included those of maternal stimulation, supportive presence, hostility (reverse scored), and respect for autonomy. They also included a rating for maternal stimulation that was scored as the number and quality of activities presumed 
to enhance perceptual, cognitive, linguistic, and physical development. Scores were equally weighted and then averaged across the assessment periods to create a single rating of sensitivity delivered by the mother. Cronbach's $\alpha$ 's for the sensitivity composites were $.75, .70, .78, .82$, and .85 at $6,15,24,36$ and 54 months, respectively. Intra-class correlations were used to calculate inter-coder reliability on the composite scores. Coefficients averaged across pairs of raters were $.87, .83, .85, .84$, and .88 at $6,15,24,36$, and 54 months, respectively. Cross-time correlations ranged from .30 to $.52(p<.0001)$. Low overall scores indicate that mothers were less involved or provided stimulation that was very poorly matched to the child's developmental level or interest. High scores indicate that mothers were sensitive to children's interest and provided ageappropriate cognitive stimulation.

Child care provider sensitivity. At 6, 15, 24, and 36, and 54 months, the child's care environment was assessed using the Observational Record of the Caregiving Environment (ORCE). Observational assessments of caregiver-child interaction were obtained in the primary non-maternal care arrangements of children who were in 10 or more hours of non-maternal care per week at each age. Observations of caregivers and children occurred during two 44-minute cycles of observation conducted on two separate days. The qualitative measures used in this analysis were collected at three equidistant points within the time-sampling periods as well as during 10 minutes at the conclusion of the three cycles. They included assessments for caregiver stimulation of cognitive development, caregiver sensitivity, caregiver detachment, and whether the caregiver established a positive emotional climate in the care environment. Each was rated on a 7-point scale. Inter-rater reliabilities ranged from .76 to .94 . Observers across all sites were certified before beginning data collection and were tested for observer drift every 3 to 4 months.

In first grade, the sensitivity and stimulation were assessed through the Classroom Observation System (COS). Observers made time-sampled records of context and of children's behavior for a total of 60 minutes (first grade) spread across the morning, and observers made qualitative or global ratings of classroom contexts and children's behavior on a scale of 1 to 7 before and after the time-sampling sessions (NICHD ECCRN, 2002, $2005 \mathrm{~b}$ ). On the basis of factor analyses and theoretical coherence, two aggregate measures of classroom context were created: instructional support for student learning (stimulation) and emotional support (sensitivity). These composite global measures of first-grade stimulation and sensitivity were averaged together to serve as a concurrent control variable in analyses that examine how predictor variables of experienced sensitivity and stimulation from 6 to 54 months relate to first-grade outcomes. 
Hours in non-maternal care. As an additional control variable, we added the average number of hours that the target child spent in nonmaternal care at each age from 6 months to 54 months. Average hours in non-maternal care is related to maternal and caregiver sensitivity (NICHD ECCRN, 1999). Hours in care is a maternal report variable based on how many hours the child spent weekly in regular non-maternal care since the time of the last telephone interview. These data were collected every 3 months up to 36 months and approximately every 4 months from 36 to 54 months of age.

\section{Child Outcomes at 54 Months and in First Grade}

Child outcomes were selected that measured language prior to entry to school and measured academic achievement and attention at the end of first grade.

Language competence was assessed at 54 months using the Preschool Language Scale (PLS-3; Zimmerman, Steiner, \& Pond, 1979). It measures a range of language behaviors, including vocabulary, morphology, syntax, and integrative thinking, which are grouped into two subscales: auditory comprehension and expressive language (Cronbach $\alpha$ 's $=.89$ and .92 , respectively, in the current study). These scales were highly correlated ( $r=$ $.70, p<.001$ in our sample). The test is standardized to have a mean of 100 and a standard deviation of 15 . In our sample, scores ranged from 50 to 133 $(M=99.39, S D=18.43)$. The PLS-3 correctly identified 4-year-olds with language disorders $80 \%$ of the time, and it was correlated with other language measures ( $r=.66-.82$, see Zimmerman et al., 1979).

Pre-academic skills in first grade were measured with two subtests of the Woodcock Johnson Achievement and Cognitive Batteries (Woodcock \& Johnson, 1990). The Letter-Word Identification Test measures skills at identifying letters and words. The Applied Problems Test measures skill in analyzing and solving practical problems in mathematics. Each standard score has a mean of 100 and standard deviation of 15 within the norming population. Within our sample, both scales were reliable based on internal consistency $(\alpha$ $>.90)$. Because the scales were highly correlated $(r=.57)$, a summary academic skills score was computed as the mean of the two scale scores.

At first grade, attention was also measured. The Continuous Performance Task (CPT; Rosvold, Mirsky, Sarason, Bransome, \& Beck, 1956) was administered to measure errors of omission as a measure of sustained attention. The child was asked to press the button "as fast as you can" each time a target stimulus (a chair) appeared on a monitor screen. A total of 220 stimuli were presented in 22 blocks. Errors of omission occurred when children failed to press the button in response to the appearance of the target 
stimulus. A log transformation was applied because of the marked skew in the data obtained.

\section{Data Analysis}

Growth curve analyses were conducted (1) to describe patterns of change over time in the sensitivity and stimulation children experienced from their mothers and from their various child care providers, and (2) to determine the extent to which these patterns from one or both sources predicted language and academic outcomes at entry to school. It is important to note that the predictor in these analyses is not the person delivering the sensitive and stimulating care, but rather the care as experienced by the child. In home assessments, the person (here the mother) and the measure of experienced care are one and the same. In the child care environment, however, the critical variable is experienced care, not the provider who delivers that care. Thus, experienced care over time is the predictor for all of the analyses to be reported. There is a precedent in the literature for examining growth curve analyses and individual variation using predictors of this type (NICHD ECCRN, 2002). It is also interesting to note that given the way we are using the models in this analyses, we are not looking at "growth" over time but rather at change over time. We pursued these questions using both variable-centered and person-centered growth curve methods.

The most commonly used variable-centered approach, the hierarchical linear model (HLM), describes intra-individual developmental patterns (here, in care experienced by different children) and identifies interindividual predictors of developmental patterns (Laird \& Ware, 1982; Raudenbush \& Bryk, 2002; Singer \& Willett, 2003). This approach estimates an individual growth curve for each individual from his or her repeated assessments of experienced care in the home or care environment. For each individual in these analyses, experienced care is defined through an intercept estimated to describe the level of the outcome at a particular age and through a slope estimated to describe the rate of change over time. These individual developmental indices become predictors of interest and can be related to outcomes of interest. ${ }^{1}$

1. The model for linear change with one grouping variable is as follows:

$Y_{i j k}=\left(\beta_{0 k}+\pi_{0 i k}\right)+\left(\beta_{1 k}+\pi_{1 i k}\right) A e_{i j k}+e_{i j k}$

for $\mathrm{i}=1, \ldots, \mathrm{n}$ individuals,

$\mathrm{j}=1, \ldots, \mathrm{p}$ occasions,

$\mathrm{k}=1, \ldots, \mathrm{r}$ groups;

with 2 fixed-effect variables: Group and Age

and 4 random variables: $Y, e, \pi_{0 i k} \pi_{1 i k}$; 
The HLM simultaneously estimates the individual and group curves. The individual growth curves are estimated using empirical Bayesian or maximum likelihood methods using both the individual's and the entire sample's data. Group growth curve parameters are estimated as the weighted mean of the corresponding individual curve parameters from the individuals in that group. The weights smooth the individual growth curves toward the group growth curve if they appear too deviant, with error assumed to be the reason that individual curves deviate from the group curve. This smoothing of individual curves and weighting of group curve parameters has been referred to as borrowing strength, and it can greatly increase the precision of parameter estimates and the power to identify predictors of developmental patterns (Raudenbush \& Bryk, 2002; Singer \& Willett, 2003).

Prototypic growth curve methods are referred to as person-centered analyses of longitudinal data (Bergman, 2001). They are based on the assumption that the population sampled comprises a small number of qualitatively different latent growth curves (Burchinal \& Appelbaum, 1991). It is assumed that the latent growth curves differ markedly from each other and that these latent curves account for the individual differences observed in patterns of change over time in an outcome of interest. Currently, trajectory analysis as developed by Nagin and Tremblay (1999) is the most popular method of person-centered growth curve analysis. These trajectory analyses assume the presence of distinct groups of children in terms of the growth trajectories on the sensitivity of care they experienced either at home or in child care. A polynomial model is used to describe the sensitivity and stimulation that children experienced between 6 and 54 months of age so that different trajectory groups be identified that can show different patterns of change ranging from no change through the patterns specified by the highest-order polynomial model specified (i.e., if a linear model is specified, the identified latent profiles can include either positive linear change or negative linear change). The method allows for missing observations and for censored measurement distributions that result in clustering at the scale's minimum or maximum. ${ }^{2}$

This method requires the analyst to specify the number of groups present in the population. However, Nagin and Tremblay (1999) have developed a method to guide the user in selecting the optimal number of groups.

\footnotetext{
2. Parameter estimates are examined for each group using the following polynomial model:

$\mathrm{y}_{i t}{ }^{*}=\beta_{0 \mathrm{j}}+\beta_{1 \mathrm{j}} \mathrm{Age}_{i t}+\beta_{2 \mathrm{j}} \mathrm{Age}^{2} \mathrm{it}+\varepsilon$

where $\mathrm{y}_{i t}{ }^{{ }_{j}}=$ outcome for person $\mathrm{i}$ at time t given membership in group $\mathrm{j}$

$\beta_{0 j}, \beta_{1 j}, \beta_{2 j}=$ coefficients describing the growth trajectory for group $j$
} 
Models are fit in succession, increasing the number of groups by one each time. The change in the Bayesian Information Criterion (BIC) is examined after each model is fit. The model with the largest BIC is accepted as containing the correct number of groups contained in the sample. Individuals are then classified into groups based on the similarity between their growth curve and group prototypic growth curves. After the group trajectories are estimated, the probability of belonging to each group is calculated and the individual is consequently assigned to the group for which it has the highest probability of membership. Once group membership has been assigned, multinomial regression can be performed to investigate the relationship between covariates and the group growth trajectories.

\section{Results}

Two sets of analyses were conducted. First, we estimated variable-centered and person-centered growth curves to describe the sensitivity of care experienced by children in interactions with their mothers and child care providers from infancy through 54 months. Second, children's outcomes were predicted from these growth curve indices in multivariate analyses of covariance to determine the extent to which different caregiving experiences over time predicted cognitive and academic skills at first grade. In the models examining outcomes, concurrent quality of parenting and teaching was controlled by including assessments of experienced sensitivity/stimulation at home and at school as covariates.

\section{Growth Curve Analyses}

Table 1 describes repeated assessments of stimulation and sensitivity experienced by children in interactions with mothers and caregivers, along with the family demographic characteristics and the first-grade cognitive and academic outcomes.

Sensitivity of care provided by mothers. The HLM (variable-centered) analysis of experienced sensitivity and stimulation delivered by mothers estimated individual linear growth curves and group quadratic curves to describe patterns of change in maternal sensitivity and stimulation in interactions with the target child from 6 months of age through 54 months (see Table 1 for descriptive statistics). Group quadratic slope parameters were used in both the HLM and trajectory analyses. In the HLM, however, only the intercept and linear slopes were estimated for each child. These individual intercepts and slopes were used as subsequent predictors of outcomes. The findings revealed that children experienced significant individual dif- 
Table 1. Sample Description

\begin{tabular}{|c|c|c|c|c|c|c|}
\hline & Child's age & $N$ & Percent & Mean & $S D$ & Range \\
\hline \multicolumn{7}{|l|}{ Demographic Characteristics } \\
\hline Maternal education & $1 \mathrm{~m}$ & 1,363 & & 14.23 & 2.51 & $7-21$ \\
\hline Gender: Male & $1 \mathrm{~m}$ & 597 & $51 \%$ & & & \\
\hline Female & $1 \mathrm{~m}$ & 564 & $49 \%$ & & & \\
\hline Ethnicity: African-American & $1 \mathrm{~m}$ & 173 & $13 \%$ & & & \\
\hline Hispanic/Latino & $1 \mathrm{~m}$ & 83 & $6 \%$ & & & \\
\hline Other & $1 \mathrm{~m}$ & 66 & $5 \%$ & & & \\
\hline White/nonHispanic & $1 \mathrm{~m}$ & 1,042 & $76 \%$ & & & \\
\hline Family income/needs ratio & $6 \mathrm{~m}-\mathrm{Gr} 1$ & 1,096 & & 3.67 & 2.74 & $.15-24.5$ \\
\hline Two-parent household & $6 m-G r 1$ & 1,097 & & .87 & .34 & $0-1$ \\
\hline M. depressive symptoms & $6 m-G r 1$ & 1,097 & & 9.23 & 6.42 & $0-37$ \\
\hline Hour/week child care & $1-54 m$ & 1,097 & & 30.1 & 14.6 & 0-74 \\
\hline \multirow[t]{6}{*}{ Maternal Sensitivity } & $6 m$ & 1,073 & & 2.92 & .50 & $1-4$ \\
\hline & $15 \mathrm{~m}$ & 1,079 & & 3.03 & .49 & $1.25-4$ \\
\hline & $24 \mathrm{~m}$ & 1,054 & & 3.03 & .57 & $1-4$ \\
\hline & $36 \mathrm{~m}$ & 1,058 & & 3.10 & .55 & $.71-4$ \\
\hline & $54 \mathrm{~m}$ & 1,035 & & 3.05 & .55 & $.71-4$ \\
\hline & Grade 1 & 1,004 & & 2.99 & .58 & $1-4$ \\
\hline \multirow[t]{6}{*}{ Caregiver-Teacher Sensitivity } & $6 \mathrm{~m}$ & 509 & & 2.99 & .58 & $1.2-4$ \\
\hline & $15 \mathrm{~m}$ & 574 & & 2.94 & .57 & $1.25-4$ \\
\hline & $24 \mathrm{~m}$ & 598 & & 2.81 & .55 & $1.07-4$ \\
\hline & $36 \mathrm{~m}$ & 648 & & 2.80 & .47 & $1.46-3.89$ \\
\hline & $54 \mathrm{~m}$ & 848 & & 2.98 & .56 & $1.13-4$ \\
\hline & Grade 1 & 962 & & 3.03 & .63 & $.76-4$ \\
\hline \multicolumn{7}{|l|}{ Child Outcomes } \\
\hline PLS Auditory comprehension & $54 \mathrm{~m}$ & 1,063 & & 98.36 & 19.92 & $50-139$ \\
\hline PLS Expressive language & $54 \mathrm{~m}$ & 1,055 & & 100.6 & 19.95 & $50-128$ \\
\hline WJ-R Applied problems & Grade 1 & 1,023 & & 110.8 & 17.1 & $46-163$ \\
\hline WJ-R Letter-word & Grade 1 & 1,025 & & 112.0 & 15.8 & $51-154$ \\
\hline WJ-R Academic & Grade 1 & 1,025 & & 111.4 & 14.60 & $69-152$ \\
\hline CPT - Omissions & Grade 1 & 996 & & 2.36 & 3.93 & $0-35.6$ \\
\hline CPT - log Omissions & Grade 1 & 996 & & .83 & .80 & $0-3.6$ \\
\hline
\end{tabular}


ferences in both their intercepts of sensitivity $\left(\chi^{2}(n=1,302, d f=1)=\right.$ $384.2, p<.001)$ and in their slopes over time $\left(\chi^{2}(n=1,302, d f=1)=8.35\right.$, $p<.01)$. Intercepts and slopes significantly correlated $(r=.31, p<.001)$. The intercept was estimated at the average age of 3 years to enhance the interpretation and power of the main effects (i.e., we had greatest power to test main effects at the mean age of data collection), and the mean estimated intercept was $\mathrm{B}=3.04$. The random-effects variance was $\sigma^{2}=.1303$. The slope described linear change over time, with an average rate of change of $\mathrm{B}=.034$ per year and a random-effect variance of $\sigma^{2}=.0026$. In addition, a nonlinear rate of change was detected $(\mathrm{B}=-.016, S E=.003)$. Individual differences in quadratic slopes were not significant, so the quadratic slope was dropped from the individual growth curve model and was retained only in the group growth curve. The HLM analysis indicated that, on average, children experience moderately sensitive and stimulating interactions with their mothers during the infant and preschool years. Mothers become slightly more sensitive over time, with slight dip in sensitivity at 15 to 24 months (the "terrible twos").

The trajectory (person-centered) analysis of maternal sensitivity estimated prototypic growth curves and classified the sensitivity and stimulation delivered by each mother into trajectory groups based on the extent to which her growth curve resembled each prototypic group curve. A quadratic growth curve model was specified, and solutions for three, four, and five prototypic groups were estimated. The four-group solution was selected as showing the most parsimonious fit to the data based on the BIC (-4248). Each of these latent profile groups was labeled based on initial sensitivity and patterns of change over time. The estimated four prototypic growth curves are shown in Figure 1 and described in Table 2. The trajectory groups differed in terms of both level and patterns of change over time. One large group emerged (labeled "moderate/increasing"), which included children whose mothers' initial sensitivity was moderately high and who became increasingly sensitive over time. The next-largest trajectory group (labeled "high/stable") included children whose mothers were consistently rated as showing high levels of sensitivity over time. The third-largest group consisted of children (labeled "moderate/stable") whose mothers were moderately sensitive consistently over time. The final, very small group involved children's experience by mothers who showed moderately low levels of sensitivity with babies at 6 months that decreased over time (labeled "low/decreasing"). In summary, the trajectory analysis identified four groups that differed largely in terms of mean level of sensitivity/stimulation experienced by the child.

Sensitivity of care by child care providers. This HLM analysis estimated individual linear growth curves and group quadratic curves to describe pat- 


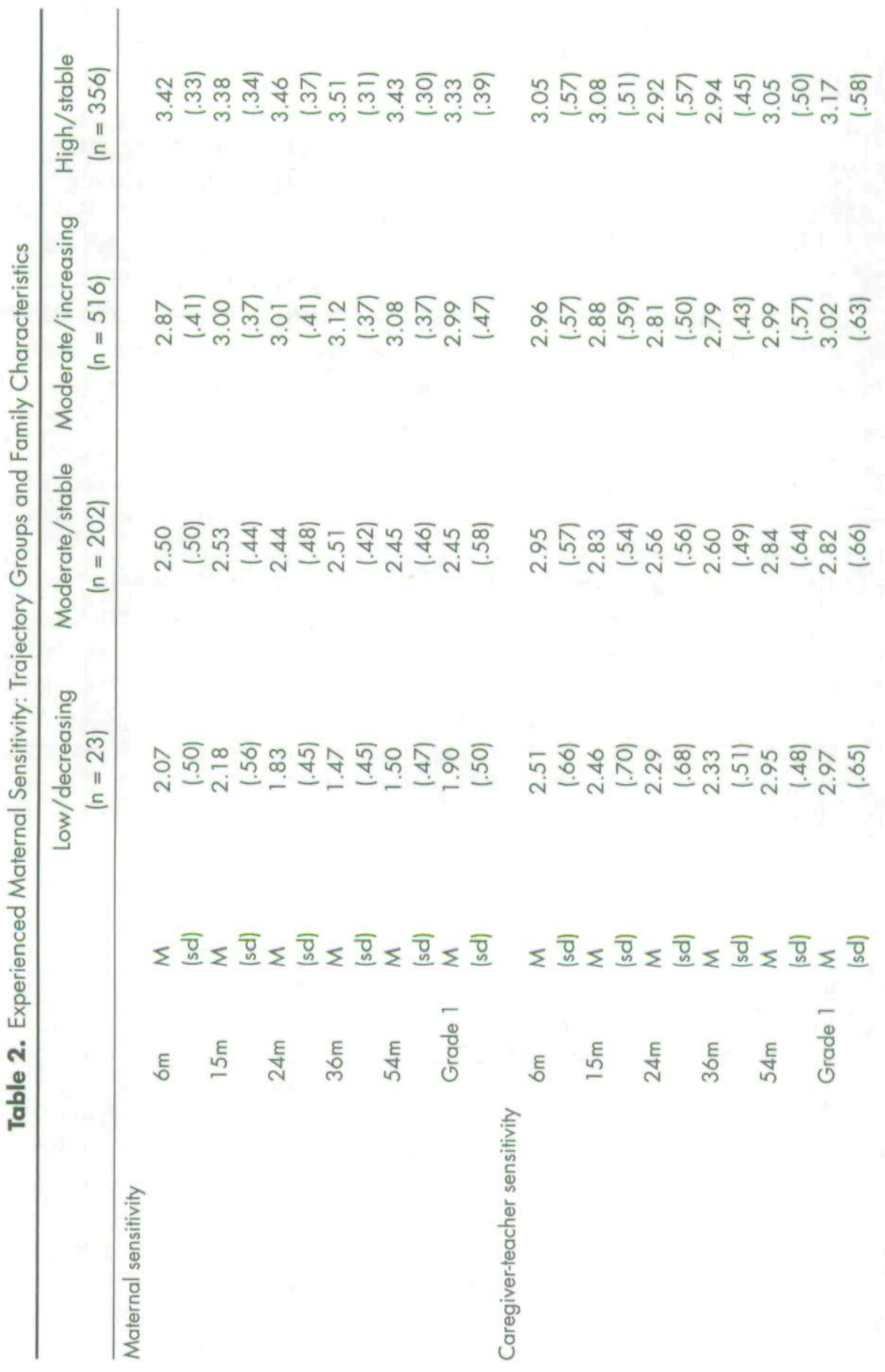




$$
\text { กุ๊ }
$$

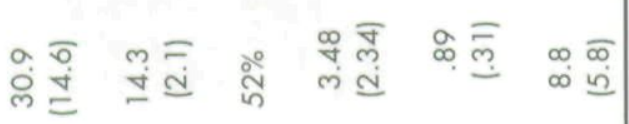

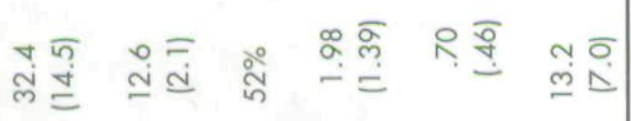

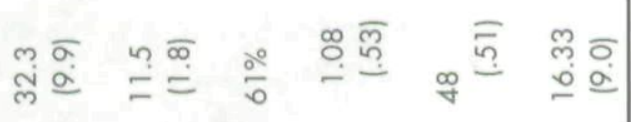

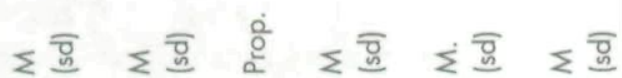

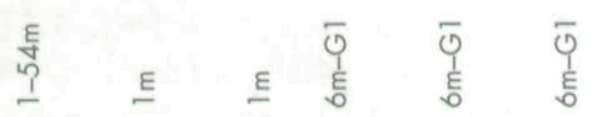

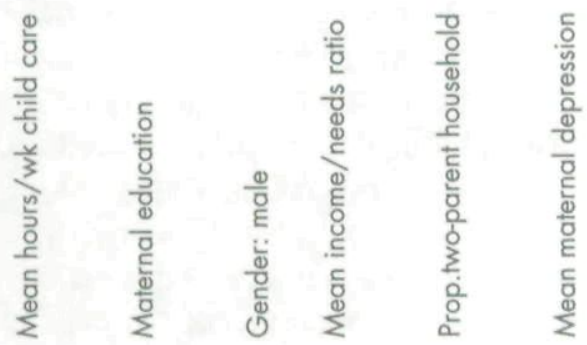




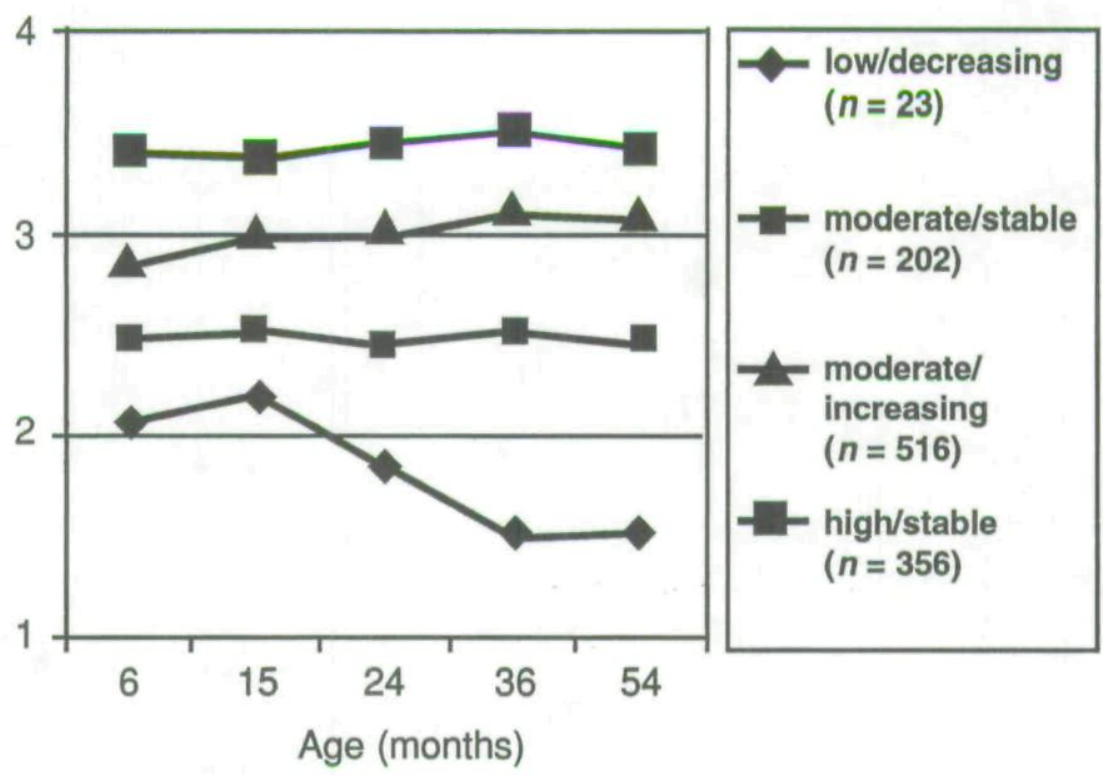

Figure 1. Child-experienced maternal sensitivity: Trajectory groups.

terns of change in sensitivity/stimulation experienced by children in interactions with the target caregivers from 6 to 54 months of age (see Table 1 for descriptive statistics). The HLM (variable-centered) analysis of caregiver sensitivity estimated individual linear growth curves and group quadratic curves to describe patterns of change in caregiver sensitivity in interactions with the target child from 6 months of age through first grade. They revealed that the child-experienced sensitivity showed significant individual differences in both intercept and overall level $\left(\chi^{2}(n=1,161, d f=1)=127.0, p<\right.$ $.001)$ and in the slope or pattern of change over time $\left(\chi^{2}(n=1161, d f=1)=\right.$ $40.6, p<.001)$. Intercepts and slopes were significantly correlated $(r=-.46)$. The intercept was estimated at the average age of 3 years, and the mean estimated intercept was $\mathrm{B}=2.83$ and random-effects variance was $\sigma^{2}=.0795$. The slope described linear change in the experienced sensitivity/stimulation over time, with a average rate of change of $\mathrm{B}=.46$ per year and a randomeffect variance of $\sigma^{2}=.0149$. In addition, a nonlinear rate of change was detected $(\mathrm{B}=.044, S E=.005)$, but individual differences in quadratic slopes were not significant and the quadratic slope was dropped from the individual growth curve model. In summary, the HLM analysis indicated that children received moderately sensitive care from child care providers, but children 
experienced more sensitive care from child care providers when they were 6- and 15-month-olds than when they were 24- and 36-month-olds. For the sample as a whole, children experienced higher sensitivity at 54 months than at 36 months, and individual differences in these improvements were not detected in the quadratic slope in individual growth curves.

The trajectory analysis of child care sensitivity estimated prototypic growth curves and classified each child into a trajectory group based on the extent to which his or her growth resembled each prototypic group curve. A quadratic growth curve model was specified, and solutions for three, four, five, and six prototypic groups were estimated. The four-group solution was selected as showing the most parsimonious fit to the data based on the BIC. The estimated four prototypic growth curves are shown in Figure 2 and described in Table 3. Again, the resulting latent profile groups were labeled based on both the initial sensitivity and patterns of change over time. The trajectory groups differ in terms of both level and patterns of change over time. One large group emerged (labeled "moderate/variable") in which caregiver sensitivity was moderately high initially and varied somewhat over time. The next-largest trajectory group (labeled "moderate/stable") included children who experienced moderately high levels of
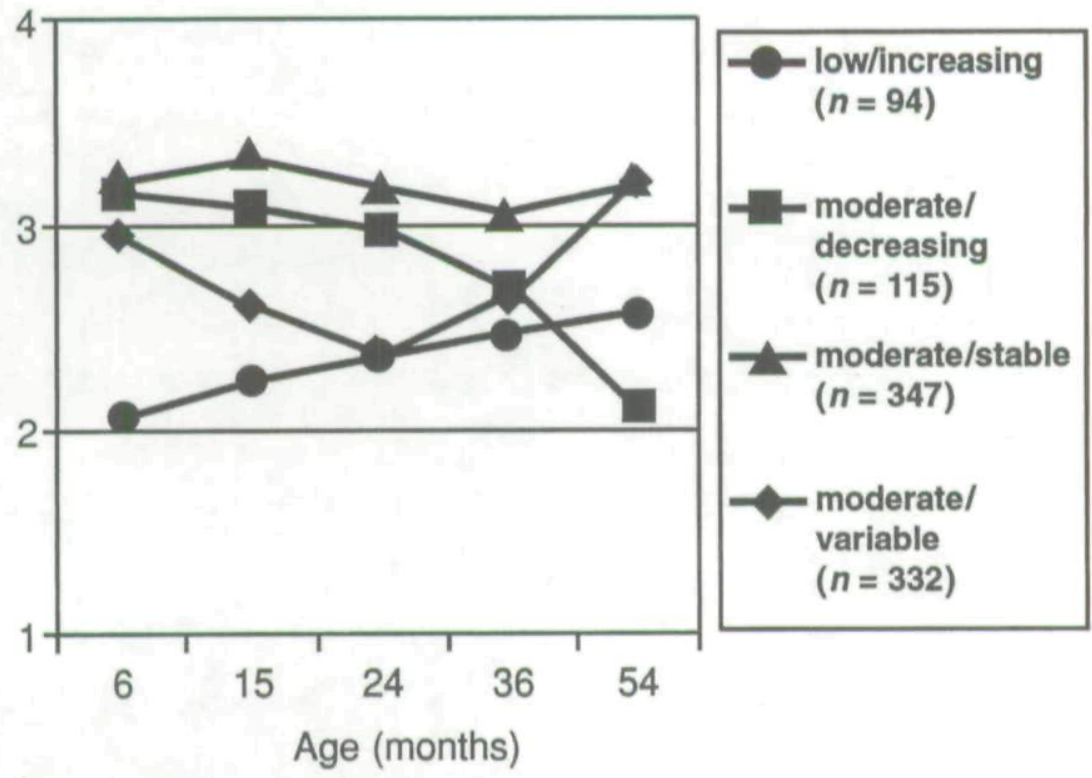

Figure 2. Child-experienced care provider sensitivity: Trajectory groups. 


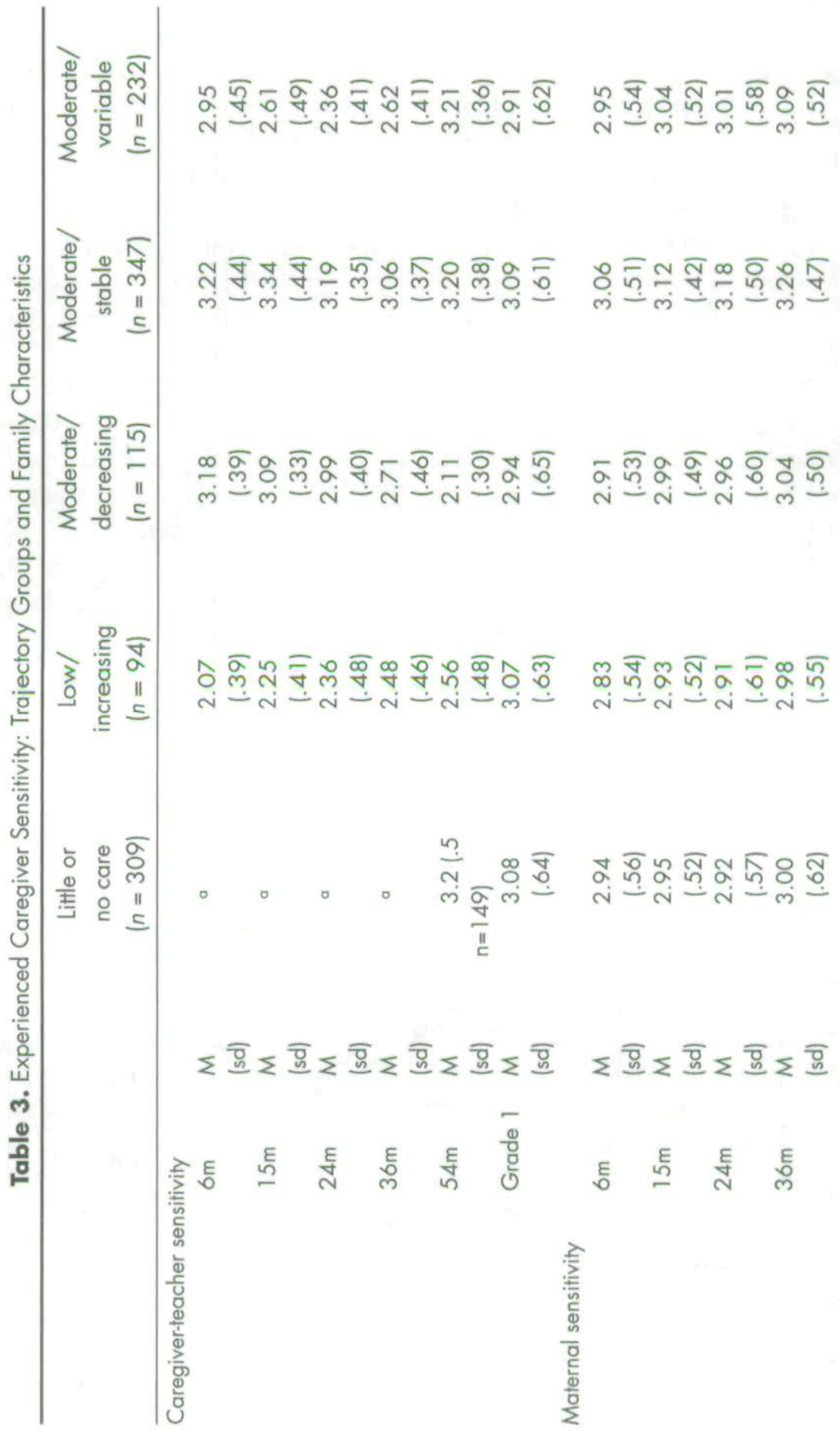




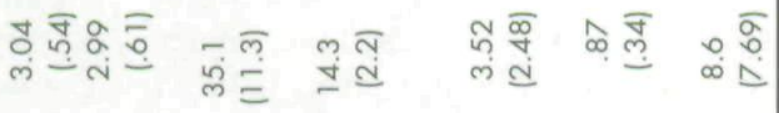

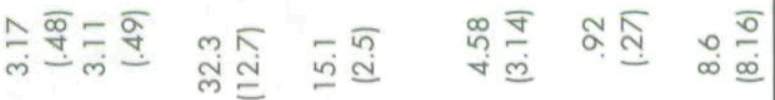

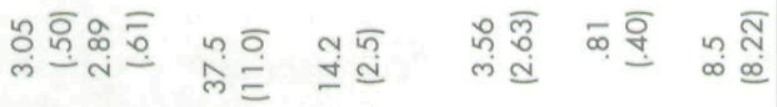

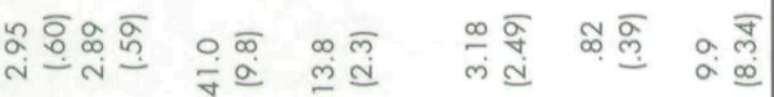

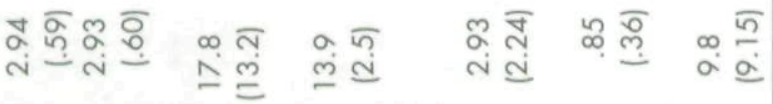

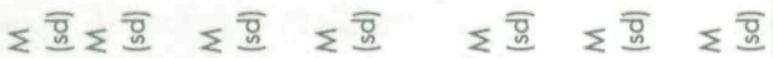

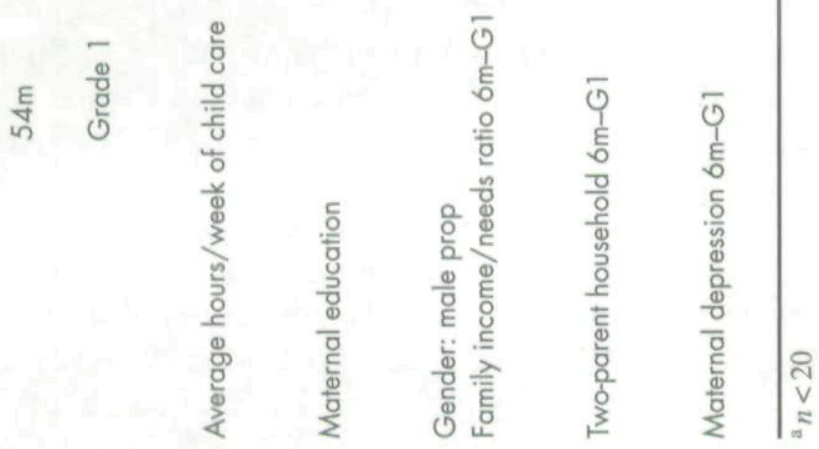


sensitivity over time. The third-largest group (labeled "moderate/decreasing") consisted of children who experienced moderate levels of sensitivity during infancy but lower levels of sensitivity during preschool years. The next group (labeled "low/increasing") included fewer children, but they experienced rather insensitive care from caregivers during infancy and more sensitive care during the preschool years. Children who were not observed in child care at least twice were lumped into a final group labeled "little or no care."

\section{Correlations Among Predictors, Covariates, and Outcomes}

Table 4 shows the correlations between the selected covariates and the individual growth curve parameters from the longitudinal measures of childexperienced sensitivity/stimulation from both mothers and caregivers. Mothers who were sensitive on average tended to show gains over time in sensitivity and stimulation. Caregiver sensitivity and stimulation toward children increased over time. However, the correlations between maternal and caregiver growth curve parameters were only modest at best. Children from more advantaged families tended to have mothers and caregivers who were more sensitive at any given time and overall. Finally, child outcomes tended to be correlated. The two PLS-3 language scores were highly correlated $(r=.70)$ and tended to be correlated with both first-grade academic achievement $(r=.56$ to .58$)$ and CPT omissions $(r=-.22$ to -.24$)$. Firstgrade academic achievement and attention were more modestly correlated $(r=-.25)$.

\section{Caregiving Sensitivity Growth Curves and Child Outcomes}

The next set of analyses asked whether first-grade outcomes differed among children who experienced different patterns of sensitivity in the care provided by either the mother or the child caregivers from infancy to school age. One set of analyses asked whether child outcomes differed as a function of the estimated intercepts and slopes from the HLM analyses of childexperienced sensitivity/stimulation care from mothers and caregivers. The other set asked whether the children in the four sensitivity trajectory groups derived from maternal interactions and the children in the four sensitivity trajectory groups derived from caregiver interactions showed different first-grade child outcomes. Interactions between maternal and caregiving sensitivity growth curve parameters were tested in preliminary analyses in the first set of analyses and between groups that experienced different patterns of maternal and caregiver sensitivity over time in the second set of 
analyses. Covariates included gender, average hours of child care per week from 6 to 54 months, and demographic characteristics (maternal education, mean income-to-needs from 6 months to first grade, and proportion of time there were two parents in the household from 6 months to first grade). These demographic and child care covariates were included because they were moderately to highly correlated with the sensitivity growth curve parameters from both mothers and caregivers (see Table 4). In addition, the sensitivity ratings of the mother and teacher when the child was in first grade were included to adjust for the quality of concurrent parenting and teaching, respectively.

Variable-centered growth curve predictors. Descriptive statistics showing correlations between individual growth curve indices generated from maternal and caregiver sensitivity and family characteristics are shown in Table 4. The correlations between first-grade outcomes and the two HLM indices of the patterns over time in the quality of maternal care that children experienced between 6 and 54 months are in the first two columns of Table 5. Correlations between child outcomes and the two HLM indices of patterns of the quality of care experienced in care child

Table 4. Correlations Between HLM Indices of Experienced Sensitivity and Family Characteristics

\begin{tabular}{|c|c|c|c|c|}
\hline & \multicolumn{2}{|c|}{ Maternal Sensitivity } & \multicolumn{2}{|c|}{ Caregiver Sensitivity } \\
\hline & Intercept & Slope & Intercept & Slope \\
\hline & $r$ & $r$ & $r$ & $r$ \\
\hline \multicolumn{5}{|l|}{ Maternal sensitivity } \\
\hline Intercept & $.67^{* *}$ & $.25^{* * *}$ & $-.07^{*}$ & \\
\hline Slope & $.14^{* * *}$ & .00 & & \\
\hline \multicolumn{5}{|l|}{ Caregiver sensitivity } \\
\hline Intercept & $.14^{* * *}$ & & $-.52^{* * *}$ & \\
\hline Slope & .00 & & & \\
\hline Maternal education & $.52^{* *}$ & $.32^{* * *}$ & $.23^{* *}$ & $-.06^{*}$ \\
\hline Family income & $.43^{* * *}$ & $.27^{\cdots *}$ & $.24^{* *}$ & $-.07^{*}$ \\
\hline Prop. partner in household & $.33^{* * *}$ & $.23^{\cdots *}$ & $.16 \%$ & -.02 \\
\hline Maternal depression & $-.37^{* * *}$ & $-.26^{* * *}$ & $-.10^{* *}$ & .01 \\
\hline Gender (male $=1)$ & $-.07^{*}$ & -.01 & -.05 & .03 \\
\hline Average hours/week of child care & $-.13^{\cdots}$ & $-.07^{*}$ & $-.20 \cdots$ & .01 \\
\hline
\end{tabular}

${ }^{*} p<.05 ;{ }^{* *} p<.01 ; * * * p<.001$ 


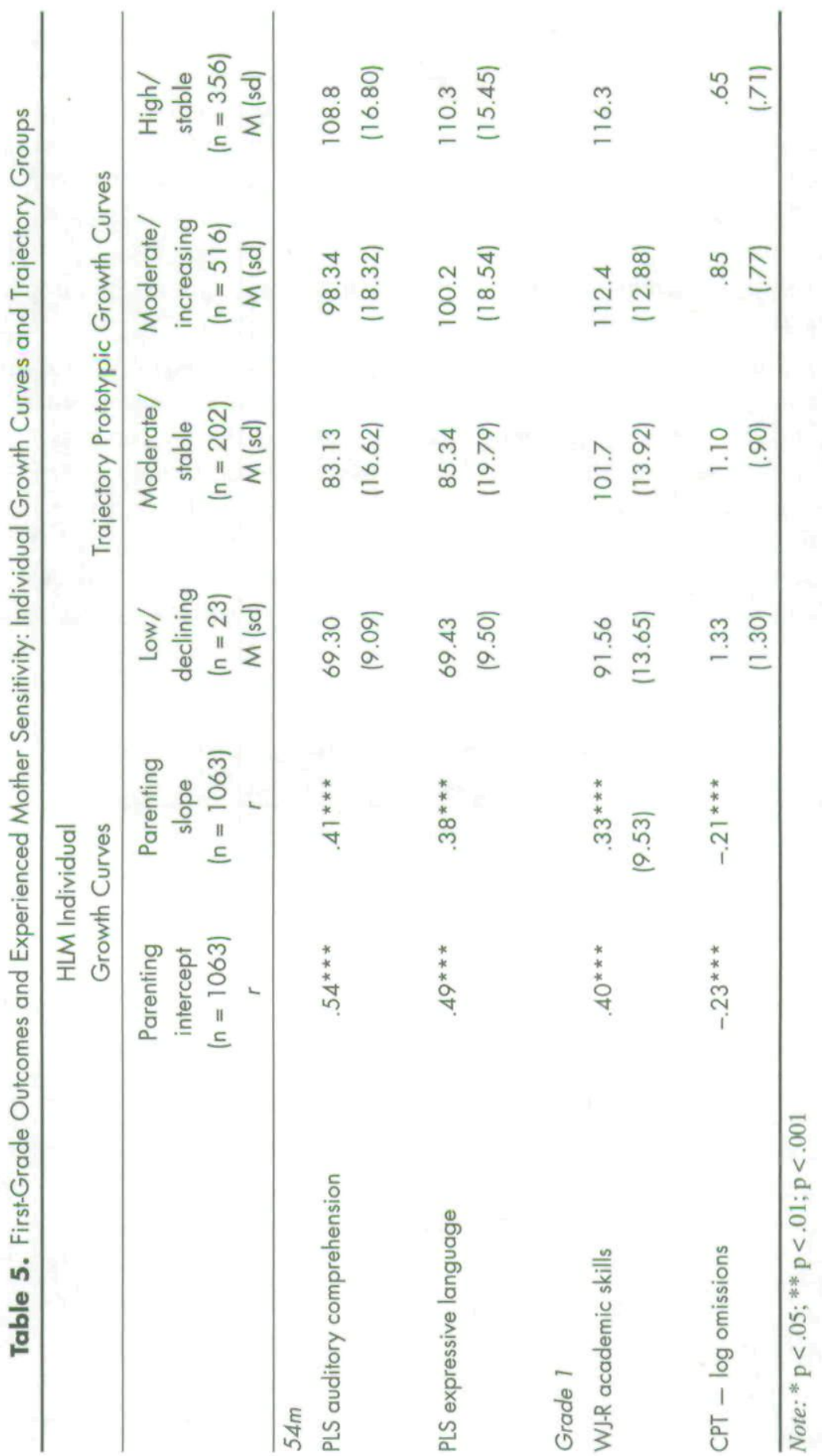


between 6 and 54 months are shown in the first two columns of Table 6 . First-grade outcomes were correlated with both the intercept and slope of the maternal sensitivity growth curves and with the intercept of the caregiver sensitivity growth curves.

Table 7 lists the results from the regression analyses. These analyses included gender, child's ethnicity, maternal education, income-to-needs ratio, household composition, and average hours of child care per week as covariates. In addition, a dummy variable was created that indicated there was insufficient information about child care provider sensitivity to estimate the caregiver sensitivity growth curve. Children without child care were included in these analyses using an econometric approach for imputing missing values (Allison, 1990). We included a dummy variable that had a value of one when a child was missing child care data and a value of zero when a child had child care data. The inclusion of this dummy variable and the assignment of mean scores to children with missing values for caregiver sensitivity allowed us to include them in the analysis in a manner that did not influence the estimation of parameters to describe the association between outcomes and caregiving sensitivity (see Allison, 1990, and NICHD \& Duncan, 2003, for full details). The interactions between maternal and caregiver growth curve parameters were dropped from the analyses when preliminary analyses suggested that those interactions were not necessary and when patterns of interactions for individual outcomes were neither consistent across correlated outcomes nor consistent with developmental theory (e.g., compensatory effects for high-quality child care for children experiencing lower or decreasing level of maternal sensitivity). Finally, first-grade quality was also dropped from preliminary analyses because it did not change observed associations and was missing for over 100 children.

The analysis focused on whether the sensitivity/stimulation intercept and slope from the mother and the sensitivity intercept and slope from the caregivers predicted first-grade outcomes. Separate block tests were conducted to test whether either the maternal or teacher sensitivity growth curve parameters added significantly to the analysis of the child outcomes (i.e., these are statistically equivalent to tests to add blocks of variables in hierarchical regression analyses). Children scored higher on language and academic tests when they experienced more sensitive caregiving from their mothers and caregivers on average over time (see Table 7). In addition, children scored higher on language, academic, and attention outcomes when mothers became increasingly more responsive and stimulating from 6 and 54 months. Similarly, children's expressive language and academic achievement were higher when caregivers became more responsive and 


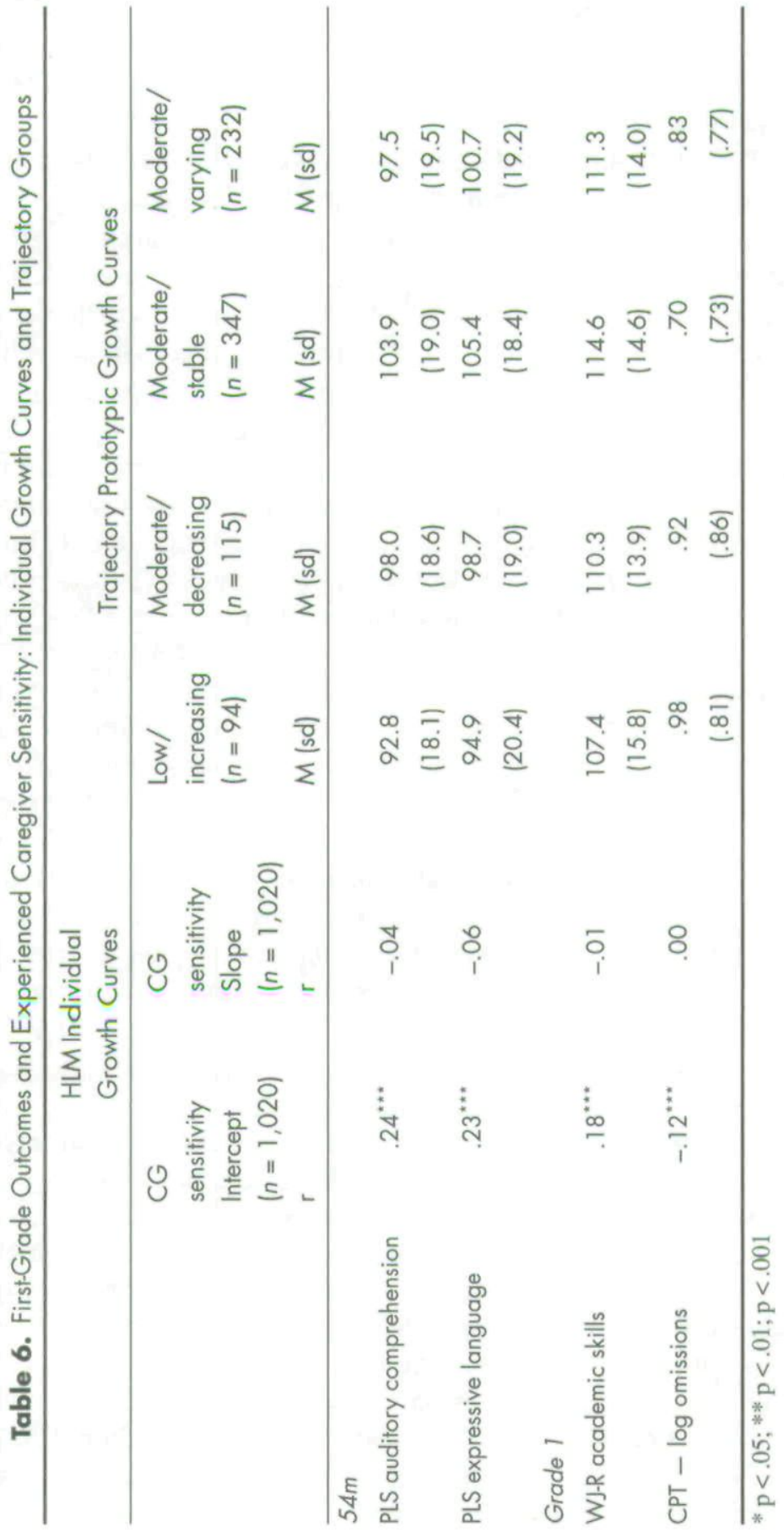


stimulating over time. Using Cohen's (1988) guidelines, effect sizes were computed based on regression coefficients and are regarded as large if the effect sizes are greater than .4, moderate if between .2 and .4 , and modest if less than .2. The effect sizes were computed to represent the anticipated change in the outcome expressed in standard deviation units associated with a $1 S D$ change in the experienced sensitivity intercept $(S D=.31)$ and slope $(S D=.27)$ from mothers and the experienced sensitivity intercept ( $S D$ $=.19)$ and slope $(S D=.07)$ from the caregiver. The effect sizes for maternal sensitivity intercepts were moderate $(d=.27-.28)$ for language and modest

Table 7. Regressions: Experienced Sensitivity From Mothers and Caregivers: Growth Curve Parameters as Predictors of Language, Academic Skills, and Attention

\begin{tabular}{|c|c|c|c|c|c|}
\hline & & $\begin{array}{l}\text { PLS } \\
\text { Auditory } \\
\text { comprehension }\end{array}$ & $\begin{array}{l}\text { PLS } \\
\text { Expressive } \\
\text { language }\end{array}$ & $\begin{array}{l}\text { WJ } \\
\text { Academic } \\
\text { achievement }\end{array}$ & $\begin{array}{l}\text { CPT } \\
\text { Attention } \\
\text { (omission) }\end{array}$ \\
\hline $\begin{array}{l}\text { Maternal sensitivity/ } \\
\text { stimulation-growth } \\
\text { curve parameters }\end{array}$ & $F(2$, , $)$ & $43.3^{* * *}$ & $46.3^{\cdots *}$ & $24.56^{\cdots}$ & $7.56^{* *}$ \\
\hline Intercept & & $.23^{* * *}$ & $.24^{* * *}$ & $.13^{* *}$ & -.04 \\
\hline Slope-linear age & & $.08^{*}$ & $.10^{* *}$ & $.13^{* *}$ & $-.11^{*}$ \\
\hline $\begin{array}{l}\text { Caregiver sensitivity/ } \\
\text { stimulation-growth } \\
\text { curve parameters }\end{array}$ & $F(2, a)$ & $3.20^{\circ}$ & $3.65^{*}$ & $3.75^{\circ}$ & 1.74 \\
\hline Intercept & & $.08^{*}$ & $.08^{*}$ & $.09^{* *}$ & -.07 \\
\hline Slope-linear age & & .03 & $.07^{*}$ & $.07^{*}$ & -.05 \\
\hline Covariates & & & & & \\
\hline Maternal education & & $.16^{* * *}$ & $.16^{* * *}$ & $.17^{* * *}$ & $-.11^{*}$ \\
\hline Income/needs & & $.12^{* * *}$ & $.08^{*}$ & .06 & -.00 \\
\hline Partner in household & & $-.07^{* *}$ & -.04 & -.02 & -.04 \\
\hline Ethnicity & $F(3,9)$ & $9.04^{* *}$ & $5.51^{* *}$ & $6.06 \%$ & 1.13 \\
\hline Gender & & $.13^{* * *}$ & $.10^{* *}$ & -.01 & -.04 \\
\hline Hours/week care & & -.01 & .01 & $.06^{\circ}$ & -.04 \\
\hline No child care & & -.04 & -.03 & -.01 & .01 \\
\hline Model R2 & $.36^{\cdots *}$ & $.31^{\cdots *}$ & $.23^{* *}$ & $.09^{* * *}$ & \\
\hline
\end{tabular}

Note: ${ }^{a}$ degrees of freedom for error are 1053 for PLS, 1023 for WJ, and 994 for CPT variables

$* \mathrm{p}<.05 ; * * \mathrm{p}<.01 ; \mathrm{p}<.001$ 
for academic outcomes $(d=.14)$, whereas effect sizes for maternal sensitivity slope and caregiver intercept and slope were modest $(.08 \leq d \leq .15)$.

Person-centered growth curve predictors. Descriptive statistics involving sensitivity trajectory groups from mothers and caregivers along with family or child care characteristics are shown in Tables 2 and 3, respectively. Those involving first-grade outcomes are shown in the final four columns of Tables 5 and 6 , respectively.

The next set of analyses asked whether child outcome differed depending on the type of change in mother and caregiver sensitivity that the children experienced. Results from ANCOVAs are shown in Table 8. The same demographic covariates were included. Analysis models, however, excluded interactions between maternal and caregiver groups and firstgrade maternal and teacher sensitivity after demonstrating similar findings with and without these terms.

A similar pattern of results obtained as were reported in the HLM analyses, although fewer associations were statistically significant. The ANCOVAs indicated that language and academic achievement outcomes differed across the four sensitivity groups derived from maternal interaction but not among the caregiver sensitivity groups. A linear pattern of differences emerged when the four maternal groups were compared. Effect sizes were computed as the difference between the adjusted group means divided by the estimated standard deviation under the analysis model, the root-mean-squared error. Using Cohen's (1988) recommendations regarding effect sizes for comparing means, differences of .7 or larger were regarded as large, .4-.7 as moderate, and less than .4 as modest. Moderate to large effect sizes emerged when the children whose mothers showed low and declining sensitivity were compared with the children whose mothers showed moderate and increasing sensitivity $(d=.52$, auditory comprehension; $d=.68$, expressive language; $d=.48$ academic achievement) or with children whose mothers showed moderately stable caregiving over time $(d$ $=1.04$, auditory comprehension; $d=1.34$, expressive language; $d=1.00$, academic achievement) and with children whose mothers who showed consistently high levels of sensitivity $(d=1.38$, auditory comprehension; $d=$ 1.54 , expressive language; $d=1.09$, academic achievement). Effects sizes were large, albeit not as large, when children whose mothers showed moderate but increasing sensitivity were compared with children whose mothers showed moderate and stable sensitivity $(d=.52$, auditory comprehension; $d=.66$, expressive language; $d=.52$, academic achievement) and with mothers who showed consistently high levels of sensitivity $(d=.86$, auditory comprehension; $d=.86$, expressive language; $d=.61$, academic achievement). Finally, smaller but significant differences were 
Table 8. Analysis of Covariance: Experienced Sensitivity from Mothers and Caregivers: Trajectory Groups as Predictors of Language, Academic Skills, and Attention

\begin{tabular}{|c|c|c|c|c|c|}
\hline & & $\begin{array}{l}\text { PLS } \\
\text { Auditory } \\
\text { comprehension }\end{array}$ & $\begin{array}{l}\text { PLS } \\
\text { Expressive } \\
\text { language }\end{array}$ & $\begin{array}{l}\text { WJ } \\
\text { Academic } \\
\text { achievement }\end{array}$ & $\begin{array}{l}\text { CPT } \\
\text { Attention } \\
\text { (omission) }\end{array}$ \\
\hline $\begin{array}{l}\text { Maternal sensitivity/ } \\
\text { stimulation }^{2}\end{array}$ & $F(3,1)$ & $24.7^{* * *}$ & $28.2^{* * *}$ & $14.2^{* * *}$ & 1.56 \\
\hline Low/decrease & $\begin{array}{l}\text { Adj } \\
M\end{array}$ & $77.8^{\circ}$ & $77.1^{\circ}$ & $97.8^{\circ}$ & \\
\hline Moderate/stable & $\begin{array}{l}\text { Adj } \\
M\end{array}$ & $86.1^{\mathrm{b}}$ & $88.5^{b}$ & $104.9^{b}$ & \\
\hline $\begin{array}{l}\text { Moderate/ } \\
\text { increasing }\end{array}$ & $\begin{array}{l}\text { Adj } \\
M\end{array}$ & $94.5^{c}$ & $99.5^{c}$ & $110.8^{c}$ & \\
\hline High/stable & $\begin{array}{l}\text { Adj } \\
M\end{array}$ & $100.0^{d}$ & $102.9^{d}$ & $112.0^{c}$ & \\
\hline $\begin{array}{l}\text { Caregiver sensitivity/ } \\
\text { stimulation }{ }^{2}\end{array}$ & $F(4,1)$ & 1.56 & 1.07 & 1.02 & 0.80 \\
\hline Covariates & & & & & \\
\hline Maternal education & $\begin{array}{l}B \\
(\mathrm{se})\end{array}$ & $\begin{array}{l}1.41^{\cdots *} \\
(.25)\end{array}$ & $\begin{array}{l}1.49^{* * *} \\
(.26)\end{array}$ & $\begin{array}{l}1.10^{* * *} \\
(.21)\end{array}$ & $\begin{array}{l}-.04 \\
(.01)^{* *}\end{array}$ \\
\hline Income/needs & $\begin{array}{l}B \\
\text { (se) }\end{array}$ & $\begin{array}{l}.92^{* *} \\
(.23)\end{array}$ & $\begin{array}{l}.69^{* *} \\
(.24)\end{array}$ & $\begin{array}{l}.39^{*} \\
(.19)\end{array}$ & $\begin{array}{l}-.00 \\
(.01)\end{array}$ \\
\hline Partner in household & $\begin{array}{l}B \\
\text { (se) }\end{array}$ & $\begin{array}{l}-3.63^{*} \\
(1.69)\end{array}$ & $\begin{array}{l}-1.62 \\
(1.76)\end{array}$ & $\begin{array}{c}-.34 \\
(1.40)\end{array}$ & $\begin{array}{l}-.12 \\
(.08)\end{array}$ \\
\hline Ethnicity & $F(3, \prime)$ & $14.78^{* *}$ & $5.44^{* * *}$ & $7.43^{\cdots *}$ & 2.52 \\
\hline Gender & $\begin{array}{l}B \\
\text { (se) }\end{array}$ & $\begin{array}{l}5.33^{* * *} \\
(.99)\end{array}$ & $\begin{array}{l}4.17^{* * *} \\
(1.04)\end{array}$ & $\begin{array}{l}-.21 \\
(.81)\end{array}$ & $\begin{array}{l}-.06 \\
(.05)\end{array}$ \\
\hline Hours/week care & $\begin{array}{l}B \\
\text { (se) }\end{array}$ & $\begin{array}{l}-.05 \\
(.04)\end{array}$ & $\begin{array}{l}-.01 \\
(.04)\end{array}$ & $\begin{array}{c}.07 \\
(.04)\end{array}$ & $\begin{array}{l}.00 \\
(.00)\end{array}$ \\
\hline Model $\mathrm{R}^{2}$ & & $.36^{* \cdots}$ & $.31^{\cdots}$ & $.22^{* * *}$ & $.08 \cdots$ \\
\hline
\end{tabular}

Note: ${ }^{1}$ degrees of freedom for error are 1053 for PLS, 1023 for WJ, and 994 for CPT variables

${ }^{2}$ adjusted means are listed when trajectory group differences were significant. Superscripts show results of pairwise comparisons. Adjusted means with different superscripts are significantly different from each other.

${ }^{*} \mathrm{p}<.05 ;{ }^{* *} \mathrm{p}<.01 ; \mathrm{p}<.00$ 
observed when children whose mothers showed moderate and stable sensitivity were compared with mothers who had consistently high levels of sensitivity ( $d=.34$, auditory comprehension; $d=.20$, expressive language; $d=$ .09 , academic achievement). Follow-up analyses indicated that similar results obtained even if first-grade assessments of sensitivity and stimulation from mothers and caregivers were included as a covariate.

\section{Discussion}

The present findings suggest three conclusions: (1) child-experienced sensitivity and stimulation from both mothers and caregivers affects child outcomes; (2) change in these aspects of children's experience through preschool is itself a predictor of child outcomes such as language, academic achievement, and attention; and (3) variable-centered and person-centered analyses offer two substantively different ways to examine the relationship of children's contexts for learning and child outcomes over time.

\section{The Case for Looking at Both Maternal and Caregiver Sensitivity}

The Committee on Family and Work Policies (2003) reported that in 1999, 9.8 million children under the age of 5 years were in some form of nonmaternal care for 40 or more hours per week. Thus, as Bronfenbrenner (1979) forcefully argues, if we are to understand how the environments that children live in affect their social and cognitive outcomes, we must look beyond single predictors like maternal or caregiver sensitivity to include the confluence of influences that might affect the child over time. Previous longitudinal studies (Burchinal et al., 2000; NICHD ECCRN, 2002) found that sensitive and responsive caregiving from both home and child care relates to language and cognitive outcomes as children enter formal schooling. The results further suggest that while the sensitivity and stimulation experienced from mothers and caregivers are modestly related, it is not the case that sensitive parents choose only sensitive caregivers for their children. Child-experienced sensitivity and responsiveness from mothers and caregivers make independent contributions to later child outcomes. Consistent with other literature, more sensitive and stimulating environments at home (Landry et al., 2001; Tamis-LeMonda \& Bornstein, 2002) and in child care (Burchinal et al., 1997, 2000; NICHD ECCRN, 2000, 2002; Peisner-Feinberg \& Burchinal, 1997) are strongly related to better outcomes for children.

Inspection of the relationships between demographic variables and child outcomes shows the expected patterns. Parents with higher income- 
to-needs ratios and better education, as well as families with two-parent households, have children with better language and academic skills. Yet, in our models, these demographic characteristics do not, in and of themselves, account for the findings. Even with these demographic variables held constant, changes in sensitive and responsive parenting and caregiving over time predict language and academic growth. These findings are consistent with others in the literature suggesting a tight relationship between sensitivity or contingent responsiveness to children and cognitive outcomes. They also extend the literature by demonstrating that overall level and patterns of change in sensitivity in both contexts during early childhood predict children's later outcomes (Landry et al., 2001).

Perhaps the most interesting finding from this study concerns the relation of child outcomes to changes over time in the experienced caregiving from mothers or caregivers. The HLM analyses indicate that language and academic skills are enhanced when mothers or caregivers become more responsive over time, regardless of initial level of responsiveness. Indeed, children's attention was related to change over time in maternal sensitivity, not to overall level of sensitivity. Thus, the current practice of using measures of maternal or caregiver sensitivity from a single time point ignores a potentially important aspect of the child's experiences at home or in child care.

Although this study breaks new ground in examining the way in which children experience both parent and caregiver sensitivity over time, it also has limitations. The first is that it is impossible from these data to examine the separable impact of stability of care and quality of care in the alternative care environment. The analyses using children in interaction with their mothers hold stability constant, thus permitting a pure examination of the ways in which fluctuations in sensitive and stimulating caregiving over time relate to changes in child outcomes. In contrast, changes in sensitivity and stimulation from caregivers over time could result from differences in the caregivers themselves or from differences in the kind of interactions that these caregivers have with children, because the study did not reliably track who the caregivers were at each age. Perhaps this is not a serious limitation, however, because the evidence presented in this study still suggests that child-experienced sensitivity and stimulation over time (be it through a person or context) relates to child outcomes.

The second limitation is that we cannot separately analyze the constructs of sensitivity and stimulation, for our operational definition of sensitivity embeds stimulation within it. This is not uncommon in the literature, for more sensitive parents are also more stimulating especially as children age (Tamis-LeMonda \& Bornstein, 2002). We fail to ask not only about different contributions of experienced sensitivity and stimulation but also 
about whether different kinds of stimulation (e.g., through play or language per se) selectively bolstered language and academic development.

\section{Experienced Sensitivity/Stimulation and Child Outcomes}

Prior longitudinal studies examined the relationship between sensitivity and stimulation and child outcome during infancy and the preschool years, but not beyond. Here we offer a glimpse of how the dynamic nature of sensitivity and stimulation in early childhood relates to language and academic achievement during the transition to school and into first grade. We chose four child outcomes that are central to school success at 54 months: language, literacy, mathematical competencies, and attention. There is abundant literature suggesting that each of these skills is important to later academic achievement, relating language at entry to school with reading (Scarborough, 2001) and math (Cocking \& Chipman, 1988; Cocking \& Mestre, 1988). Further, early reading and mathematical competencies are associated with later reading and math scores (Shonkoff \& Phillips, 2000; Storch \& Whitehurst, 2002). Theoretically, sustained attention is also central for effective learning in school (Bowman, Donovan, \& Burns, 2001; NICHD ECCRN, 2005a).

Not only are these skills pivotal for learning and school readiness, but research demonstrates that each of these outcomes is malleable and responsive to environmental variation (e.g., in language, see Hart \& Risley, 1995; in literacy, see Senechal \& Lefevre, 2002; in mathematical competencies, see Ginsburg, 1989; and in attention, see NICHD ECCRN, 2002). By using outcomes that are both critical to early school success and responsive to sensitive and responsive contexts, we were able to ask how dynamic changes in the sensitivity of caregiver and parent relate to these outcomes.

Our results suggest that parent sensitivity is important for school success. In the HLM analysis, child-experienced sensitivity from mothers across time related to all four of the outcome variables for their children. This relationship was revealed not only in the relation of school success to the intercept or average scores of children across time, but also in its relation to the slope or changing nature of sensitivity as the child grew older. Further, and importantly, in the person-centered analyses, consistently high sensitivity across time conferred a significant advantage for children even beyond that which was offered by moderate and increasing stimulation.

With caregivers, a similar though not as strong pattern emerged. Caregiver sensitivity was related to three of the four child outcomes, with attention being the only one that bore no relationship to caregiver behavior. In this analysis, the intercepts modestly predicted language and academic outcomes. 
However, in the person-centered analyses, no differences were detected in child outcomes across the four patterns of caregiver sensitivity. The caregiver profiles were also less disparate than the parent profiles for sensitivity (e.g., moderate stable sensitivity vs. moderate varying sensitivity), leaving less room for change in predictors to be reflected in later outcomes. Taken together, these results affirm the relationship between the level and change in responsive and sensitive environments and child outcomes.

\section{Variable-Centered and Person-Centered Approaches}

The conclusions presented above regarding prediction of outcomes from change and level of sensitivity are especially robust because trajectories of the child-experienced sensitivity from both mother and caregiver were characterized using both a variable-centered and a person-centered approach. The variable-centered approach assumed that there were substantial individual differences in level and rate of change but that these differences were quantitative rather than qualitative. The person-centered approach assumed that there were substantial differences in the overall shape of the trajectories but that differences among individuals showing the same trajectory pattern were minimal. With these data, the HLM approach provided more information regarding patterns of change in child-experienced sensitivity from mothers, because differences among the trajectory groups did not appear in the person-centered analyses. In contrast, the latent trajectory analysis of the degree to which children experienced changes in sensitive and responsive care in child care did reveal trajectories with different patterns of caregiver sensitivity over time. Thus, it is possible that the more informative summary of the child's experiences would be the person-oriented approach if we had detected interesting differences in child outcomes associated with these trajectory groups. Overall, the variable-centered approach appeared to provide more reliable, and perhaps valid, descriptions of patterns of change in caregiving sensitivity for mothers and caregivers, because the data matched the model assumptions of the variable-centered approach more closely than the person-centered approach.

Whereas the variable-centered approach provided better prediction in these analyses, conceptually, the person-centered approach would provide better indices of patterns of change under certain circumstances. The latter approach assumes that there are qualitatively different latent profiles and that within each profile group all individuals show very similar patterns of change over time. Therefore, the person-centered approach would likely have provided better prediction of child outcomes if we had identified groups in which either maternal or caregiver sensitivity showed markedly 
different patterns of increases or decreases over time. Given the lack of change between groups in the person-oriented approaches, it is little wonder that the trajectories they generated did not uniquely predict outcomes (Nagin \& Tremblay, 1999).

\section{Conclusion}

Results from the current study, then, demonstrate three main points. First, it is critical to examine childhood experiences that result from both parents and caregivers. Second, it is critical to examine the dynamic nature of these experiences over time. Finally, newer analytic approaches are now available to enable researchers to investigate how the changing contexts that constitute children's early environments jointly and independently contribute to later social and cognitive behaviors. Although these analyses are not typically used in the study of early cognitive development, they allow us to apply a different lens on the development of language and cognition as it unfolds through time.

\section{References}

Allison, P. (1990). Change scores as dependent variables in regression analysis. In C. C. Clogg (Ed.), Sociological methodology (pp. 93-114). Oxford: Blackwell.

Beebe, B., Jaffee, J., \& Lachman, F. M. (1992). A dyadic systems view of communication. In N. Skolnick \& S. Warshaw (Eds.), Relational perspectives in psychoanalysis (pp. 61-81). Hillsdale, NJ: Analytic Press.

Bergman, L. R. (2001). A person approach in research on adolescence: Some methodological challenges. In A. von Eye \& C. Schuster, Special Issue of the Journal of Adolescent Research, 16, 28-53.

Bornstein, M. H., \& Tamis-LeMonda, C. S. (1989). Maternal responsiveness and cognitive development in children. In M. H. Bornstein (Ed.), Maternal responsiveness: Characteristics and consequences. New directions for child development (Vol. 43, pp. 49-61). San Francisco: Jossey-Bass.

Bowman, B., Donovan, S., \& Burns, S. (Eds.). (2001). Eager to learn: Educating our preschoolers. Washington, DC: National Academy Press.

Bradley, R. H., Caldwell, B. M., Rock, S. L., Ramey, C. T., Barnard, K. E., Gray, C., Hammond, M. A., Mitchell, S., Gottfried, A. W., Siegel, L., \& Johnson, D. L. (1989). Home environment and cognitive development in the first 3 years: A collaborative study involving six sites and three ethnic groups in North America. Developmental Psychology, 25, 217-235.

Bradley, R. H., \& Corwyn, R. F. (2002). Socioeconomic status and child development. Annual Review of Psychology, 53, 371-399. 
Bradley, R. H., Corwyn, R. F., Burchinal, M. R., Pipes McAdoo, H., \& Garcia Coll, C.. (2001). The home environments of children in the United States Part II: Relations with behavioral development through age thirteen. Child Development, 72, 1868-1886.

Bronfenbrenner, U. (1979). The ecology of human development: Experiments by nature and design. Cambridge: Harvard University Press.

Bronfenbrenner, U., \& Morris, P. A. (1998) The ecology of developmental processes (1998). In W. Damon (Ser. Ed.) \& R. M. Lerner (Ed.), Handbook of child psychology. Vol. 1: Theory (5th ed., pp. 993-1028). New York: Wiley.

Burchinal, M. R., \& Appelbaum, M. (1991). Estimating individual developmental functions: Methods and their assumptions. Child Development, 62, 23-43.

Burchinal, M. R., Campbell, F. A., Bryant, D. M., Wasik, B. H., \& Ramey, C. T. (1997). Early intervention and mediating processes in cognitive performance of children of low-income African American families. Child Development, 68, 935-954.

Burchinal, M. R., Roberts, J. E., Nabors, L. A., \& Bryant, D. M. (1996). Quality of center child care and infant cognitive and language development. Child Development, 67, 606-620.

Burchinal, M. R., Roberts, J. E., Riggins, R., Zeisel, S. A., Neebe, E., \& Bryant, D. (2000). Relating quality of center-based child care to early cognitive and language development longitudinally. Child Development, 71, 338-357.

Clarke-Stewart, K. A. (1973). Interactions between mothers and their young children: characteristics and consequences. Monographs of the Society for Research in Child Development, 38.

Clarke-Stewart, K. A., Vandell, D. L., Burchinal, M., O'Brien, M., \& McCartney, K., (2002). Do regulable features of child-care homes affect children's development? Early Childhood Research Quarterly, 17, 52-86.

Cocking, R., \& Chipman, S. (1988). Conceptual issues related to mathematic achievement of language minority children. In R. Cocking \& J. Mestre (Eds.), Linguistic and cultural influences on learning mathematics (pp. 17-46). Hillside, NJ: Erlbaum.

Cocking, R., \& Mestre, J. (1988). Introduction: Considerations of language mediators of mathematics learning. In R. Cocking \& J. Mestre (Eds.), Linguistic and cultural influences on learning mathematics (pp. 3-16). Hillside, NJ: Erlbaum.

Cohen, J. (1988). Statistical power analysis for the behavioral sciences. Hillsdale, NJ: Erlbaum.

Committee on Family and Work Policies. (2003). Working families and growing kids: Caring for children and adolescents. Washington, DC: National Academic Press.

Cunningham, A. E., \& Stanovich, K. E. (1997). Early reading acquisition and its relation to reading experience and ability 10 years later. Developmental Psychology, 33, 934-945. 
Cunningham, A. E., Stanovich, K. E., \& West, R. F. (1994). Literacy environment and the development of children's cognitive skills. In E. M. H. Assink (Ed.), Literacy acquisition and social context (pp. 70-90). Oxford, UK: Harvester Wheatsheaf/Prentice Hall.

Dunn, L. (1993). Proximal and distal features of day care quality and children's development. Early Childhood Research Quarterly, 8, 167-192.

Estrada, P., Arsenio, W. F., Hess, R. D., \& Holloway, S. (1987). Affective quality of the mother-child relationship: Longitudinal consequences. Developmental Psychology, 23, 210-215.

Ginsburg, H. (1989). Children's arithmetic: How they learn it and how you teach it. Austin, TX: Pro Ed.

Hart, B., and Risley, T. R. (1995). Meaningful differences in the everyday experiences of young American children. Baltimore: Brookes.

Hart, B., and Risley, T. R. (1999). The social world of children learning to talk. Baltimore: Brookes.

Hoff, E. (in progress). How social environments support and shape language development.

Hoff, E., \& Naigles, L. (2002). How children use input to acquire a lexicon. Child Development, 73, 418-433.

Howes, C. (2000). Social-emotional classroom climate in child care, child-teacher relationships and children's second grade peer relations. Social Development, 9(2), 191-204.

Howes, C., Phillips, D. A., \& Whitebook, M. (1992). Thresholds of quality: Implications for the social development of children in center-based child care. Child Development, 63, 449-460.

Huttenlocher, J., Haight, W., Bryk, A., Seltzer, M., \& Lyons, T. (1991). Early vocabulary growth: Relation to language input and gender. Developmental Psychology, 27, 236-248.

Katz, J. R., (2000). Young children's verbalizations of relationship: A measurement pilot. Qualifying Paper-Harvard Graduate School of Education.

Kontos, S. J. (1991). Child care quality, family background, and children's development. Early Childhood Research Quarterly, 6, 249-262.

Kontos, S., Howes, C., Shinn, M., \& Galinsky, E. (1997). Children's experiences in family child care and relative care as a function of family income and ethnicity. Merrill-Palmer Quarterly, 43, 386-403.

Laird, N. M., \& Ware, J. H. (1982). Random-effects models for longitudinal data. Biometrics, 38, 963-974.

Landry, S. H., Smith, K. E., Swank, P. R., Assel, M. A., \& Vellet, S. (2001). Does early responsive parenting have a special importance for children's development or is consistency across early childhood necessary? Developmental Psychology, 37, 387-403. 
Landry, S. H., Smith K. E., Swank, P. R., \& Miller-Loncar, C. L. (2000). Early maternal and child influences on children's later independent cognitive and social functioning. Child Development, 71, 358-375.

Love, J. M., Harrison, L., Sagi-Schwartz, A., van IJzendoorn, M. H., Ross, C., Ungerer, J. A., Raikes, H., Brady-Smith, C., Boller, K., Brooks-Gunn, J., Constantine, J., Kisker, E. E., Paulsell, D., \& Chazan-Cohen, R. (2003). Child care quality matters: How conclusions may vary with context. Child Development, 74, 1021-1033.

McCartney, K. (1984). Effect of quality of day care environment on children's language development. Developmental Psychology, 20, 244-260.

Morrison, F. J., \& Cooney, R. R. (2002). Parenting and academic achievement: Multiple paths to early literacy. In J. G. Borkowski, C. Ramey, S. Landesman, et al. (Eds.), Parenting and the child's world: Influences on academic, intellectual, and social-emotional development (pp. 141-160). Mahwah, NJ: Erlbaum.

Nagin, D., \& Tremblay, R. E. (1999). Trajectories of physical aggression, opposition, and hyperactivity on the path to physically violent and nonviolent juvenile delinquency. Child Development, 70, 1181-1196.

Newport, E., Gleitman, H., \& Gleitman, L. (1977). Mother, I'd rather do it myself: Some effects and noneffects of maternal speech style. In C. E. Snow \& C. A. Ferguson (Eds.), Talking to children: Language input and acquisition (pp. 109-150). Cambridge: Cambridge University Press.

NICHD Early Child Care Research Network. (1999). Child care and mother-child interactions in the first three years of life. Developmental Psychology, 35, 1399-1413.

NICHD Early Child Care Research Network. (2000). The relation of child care to cognitive and language development. Child Development, 71, 958-978.

NICHD Early Child Care Research Network. (2002). Early child care and children's development prior to school entry: Results from the NICHD Study of Early Child Care. American Educational Research Journal, 39, 133-164.

NICHD Early Child Care Research Network. (2004). Affect dysregulation in the mother-child relationship in the toddler years: Antecedents and consequences. Development and Psychopathology, 16(1), 43-68.

NICHD Early Child Care Research Network. (2005a). Predicting individual differences in attention, memory, and planning in first graders from experiences at home, child care, and school. Developmental Psychology, 41, 99-115.

NICHD Early Child Care Research Network. (2005b). Early child care and children's development in the primary grades: Results from the NICHD Study of Early Child Care. American Educational Research Journal, 43, 537-570.

NICHD Early Child Care Research Network \& Duncan, G. J. (2003). Modeling the impacts of child care quality on children's preschool cognitive development. Child Development, 74, 1454-1475. 
Peisner-Feinberg, E. S., \& Burchinal, M. R. (1997). Relations between preschool children's child-care experiences and concurrent development: The Cost, Quality, and Outcomes Study. Merrill-Palmer Quarterly, 43, 451-477.

Raudenbush, S., \& Bryk, A., (2002). Hierarchical linear model: Applications and data analysis methods (2nd ed.). New York: Sage.

Rosvold, H. E., Mirsky, A. F., Sarason, I., Bransome, E. D., Jr., \& Beck, L. H. (1956). A continuous performance test of brain damage. Journal of Consulting Psychology, 20, 343-350.

Sameroff, A. J., \& Seifer, R. (1983). Familial risk and child competence. Child Development, 54, 1254-1268.

Scarborough, H. S. (2001). Connecting early language and literacy to later reading (dis)abilities: Evidence, theory, and practice. In S. B. Neuman \& D. K. Dickinson (Eds.), Handbook of early literacy research (pp. 97-110). New York: Guilford.

Scarborough, H. S., Dobrich, W., \& Hagar, M. (1991). Preschool literacy experience and later reading achievement. Journal of Learning Disabilities, 24, 508-511.

Schliecker, E., White, D. R., \& Jacobs, E.. (1991). The role of day care quality in the prediction of children's vocabulary. Canadian Journal of Behavioral Science, 23(1), 12-24.

Senechal, M., \& LeFevre, J. (2002). Parental involvement in the development of children's reading skill: A five-year longitudinal study. Child Development, 73, 445-460.

Shonkoff, J. P., \& Phillips, D. A. (Eds.). (2000). From neurons to neighborhoods: The science of early childhood development. Washington, DC: National Academy Press.

Singer, J. D., \& Willett, J. B. (2003). Applied longitudinal data analysis: Modeling change and event occurrence. New York: Oxford University Press.

Snow, C. E. (1986). Conversations with children. In P. Fletcher, \& M. Garman (Eds.), Language acquisition (pp. 363-375). Cambridge: Cambridge University Press.

Storch, S. A., \& Whitehurst, G. J. (2002). Oral language and code-related precursors to reading: Evidence from a longitudinal model. Developmental Psychology, 38, 934-947.

Tamis-LeMonda, C. S., \& Bornstein, M. H. (2002). Maternal responsiveness and early language acquisition. Advances in child development \& behavior, 29, 89-127.

Tamis-LeMonda, C. S., Bornstein, M. H., \& Baumwell, L. (2001) Maternal responsiveness and children's achievement of language milestones. Child Development, 72, 748-767 
Tomasello, M., \& Farrar, J. (1986). Joint attention and early language. Child Development, 57, 1454-1463.

Wakschlag, L. S., \& Hans, S. L. (1999). Relation of maternal responsiveness during infancy to the development of behavior problems in high-risk youths. Developmental Psychology, 31, 147-169.

Weizman, Z. O., \& Snow, C. E. (2001). Lexical input as related to children's vocabulary acquisition: Effects of sophisticated exposure and support for meaning. Developmental Psychology, 37, 265-279.

Whitehurst, G. J., Arnold, D. S., Epstein, J. N., \& Angell, A. L. (1994). A picture book reading intervention in day care and home for children from low-income families. Developmental Psychology, 30, 679-689.

Woodcock, R. W., \& Johnson, M. B. (1990). Tests of achievement, WJ-R. Examiner's manual. Allen, TX: DLM Teaching Resources.

Zill, N. (1999). Promoting educational equity and excellence in kindergarten. In R. C. Pianta \& M. Cox (Eds.), The transition to kindergarten (pp. 67-105). Baltimore: Brookes.

Zimmerman, I. L., Steiner, \& Pond, R. E. (1979). Preschool Language Scale. San Antonio, TX: Psychological Corporation. 
Copyright of Merrill-Palmer Quarterly is the property of Wayne State University Press and its content may not be copied or emailed to multiple sites or posted to a listserv without the copyright holder's express written permission. However, users may print, download, or email articles for individual use. 